UDC 615.213

DOI: $10.15587 / 2519-4852.2021 .249375$

\title{
LOW-DOSE DIGOXIN ENHANCES THE ANTICONVULSIVE POTENTIAL OF CARBAMAZEPINE AND LAMOTRIGINE IN CHEMO-INDUCED SEIZURES WITH DIFFERENT NEUROCHEMICAL MECHANISMS
}

\author{
Vadim Tsyvunin, Sergiy Shtrygol’, Ihnat Havrylov, Diana Shtrygol' \\ "Non-antiepileptic" drugs have a strong potential as adjuvants in multidrug-resistant epilepsy treatment. In previ- \\ ous study the influence of low doses of digoxin, which do not affect the myocardium, on the anticonvulsant potential \\ of classical commonly used anti-epileptic drugs under conditions of seizures, induced by pentylenetetrazole and \\ maximal electroshock, has been investigated.
}

The aim of the study was to investigate the influence of digoxin at a sub-cardiotonic dose on the anticonvulsant potential of carbamazepine and lamotrigine in experimental seizures with different neurochemical mechanisms.

Material and methods. A total of 192 random-bred male albino mice weighting 22-25 g were used. Carbamazepine and lamotrigine were administered intragastrically in conditionally effective $\left(E D_{50}\right)$ and sub-effective $(1 / 2$ $\left.E D_{50}\right)$ doses: carbamazepine at doses of 100 and $50 \mathrm{mg} / \mathrm{kg}$; lamotrigine at doses of 25 and $12.5 \mathrm{mg} / \mathrm{kg}$. Digoxin was administered subcutaneously at a sub-cardiotonic dose of $0.8 \mathrm{mg} / \mathrm{kg}$ as an adjuvant to carbamazepine and lamotrigine in $1 / 2 E_{50}$. Picrotoxin (2.5 $\mathrm{mg} / \mathrm{kg}$ subcutaneously); thiosemicarbazide (25 $\mathrm{mg} / \mathrm{kg}$ intraperitoneally); strychnine (1.2 mg/kg subcutaneously); camphor (1000 mg/kg intraperitoneally) were used as convulsant agents.

Results. It was found that digoxin not only has its own permanent anticonvulsant effect on different models of paroxysms with different neurochemical mechanisms of development, but also significantly enhances the anticonvulsant potential of carbamazepine (to a lesser extent-lamotrigine) regardless of the pathogenesis of experimental paroxysms.

Conclusion. Based on the results, it can be concluded that digoxin has a high potential as an adjuvant medicine in complex epilepsy treatment because it enhances the efficiency of low-dose traditional anticonvulsants carbamazepine and lamotrigine

Keywords: anti-epileptic drugs, digoxin, adjuvant, chemo-induced seizures, mice

\author{
How to cite: \\ Tsyvunin, V., Shtrygol', S., Havrylov, I., Shtrygol', D. (2021). Low-dose digoxin enhances the anticonvulsive potential of carbamazepine and \\ lamotrigine in chemo-induced seizures with different neurochemical mechanisms. ScienceRise: Pharmaceutical Science, 6 (34), 58-65. doi: \\ http://doi.org/10.15587/2519-4852.2021.249375 \\ (C) The Author(s) 2021 \\ This is an open access article under the Creative Commons CC BY license hydrate
}

\section{Introduction}

Despite a wide range of modern antiepileptic drugs (AEDs), most of which also have multiple mechanisms of influence on the development of seizures [1, 2], every fourth patient with epilepsy is multidrug-resistant $[3,4]$. In parallel with the development of the latest AEDs, the search for promising correctors of refractory epilepsy among drugs of different pharmacological groups - the so-called "non-antiepileptic" drugs (nonAEDs) [5]. Among such drugs, antiarrhythmic drugs deserve the highest attention - sodium, potassium and calcium channel blockers, as well as cyclooxygenase inhibitors, interleukin antagonists, angiotensin II receptor blockers, etc. [5-8]. The effect of such drugs on certain links in the epilepsy pathogenesis is exactly unknown. The authors suggest that their anticonvulsant effect may be associated with blockade of transmembrane currents of sodium, potassium and calcium (particularly for antiarrhythmic drugs of I-IV classes according to the Vaughan-Williams classification), or reduction of neuroinflammation (for cyclooxygenase inhibitors, interleukin antagonists), etc. It has been found, however, that the anticonvulsant activity of non-AEDs per se is moderate, but the addition of such drugs to traditional - classical - AEDs in various regimens for refractory epilepsy allows to achieve much more stable disease control [9]. In addition, antiepileptic drugs have their own side effects (including AV blockade or sinus blockade for antiarrhythmic drugs, ulcerogenic effect for cyclooxygenase inhibitors, hypotension for angiotensin II receptor blockers), which justifies the advisability of further studies of their use in adjuvant therapy of epilepsy.

One such non-AEDs with previously experimentally and clinically proven anticonvulsant activity is the known cardiac glycoside digoxin at a sub-cardiotonic doses that do not cause side effects $[10,11]$. We have previously investigated the effect of low doses of digoxin, which do not affect the myocardium, on the anticonvulsant potential of seven classical commonly used AEDs with different mechanisms of influence on the molecular mechanisms of epileptogenesis [12, 13]. It was found that in the basic models of primary generalized seizures paroxysms, induced by pentylenetetrazole and maximal electroshock - digoxin in a sub-cardiotonic dose signifi- 
cantly potentiates the anticonvulsant action of valproate, carbamazepine, levetiracetam, lamotrigine, topiramate, clonazepam and phenobarbital $[12,13]$. There is, however, the question of an in-depth study of the effect of digoxin on various neurochemical links in the development of seizures, as well as the possible modulation of molecular receptor mechanisms and, as a consequence, the anticonvulsant action of classical AEDs.

Therefore, the aim of this work was to investigate the influence of digoxin at a sub-cardiotonic dose on the anticonvulsant potential of carbamazepine and lamotrigine in experimental seizures with different pathogenesis.

\section{Planning (methodology) of the research}

The methodology was designed as following Fig. 1 according to the aim of the research.

The research was performed using mice as a convenient universal test system in the study of anticonvulsant effect of drugs [14].

The models of chemo-induced seizures were chosen taking into account different molecular mechanisms of convulsions development [15] and, as a consequence, the abilit to establish the neurochemical links of the anticonvulsant action realization for digoxin and its combinations with carbamazepine and lamotrigine. Unlike the basic models of pentylenetetrazole-induced seizures and maximal electroshock, which are used for the initial screening of compounds, these models are used by the court for in-depth study of the anticonvulsant action of promising anticonvulsant drugs $[15,16]$. Carbamazepine and lamotrigine have been selected as widely used drugs for first-line treatment of epilepsy $[1,2,5]$.

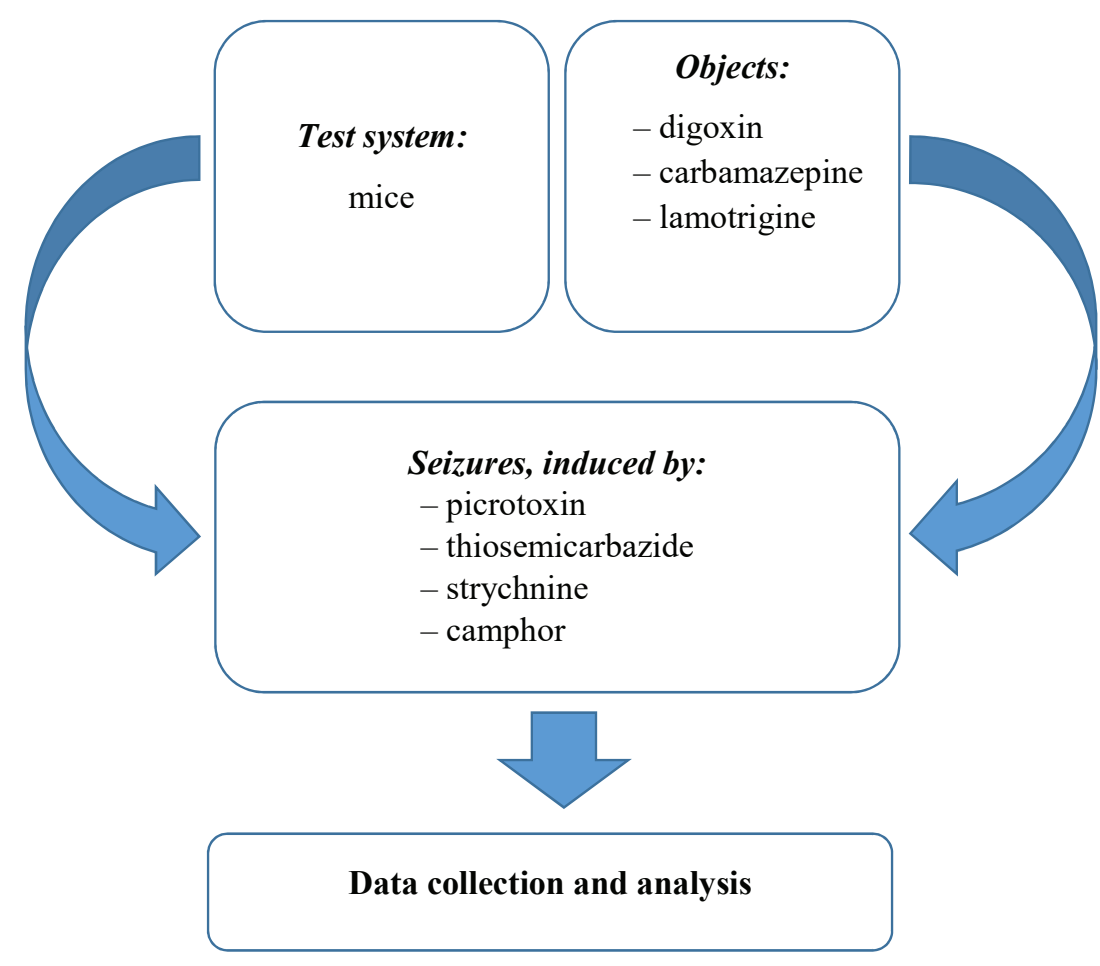

Fig. 1. Algorithm of the research

\section{Material and methods}

Experiments were conducted from February to

March 2021.
192 random-bred male albino mice weighting 22 $25 \mathrm{~g}$ were used in the experiments. Animals were kept in standard laboratory conditions at constant humidity and temperature $+18-20^{\circ} \mathrm{C}$, food and water ad libitum, in the Central Research Laboratory of Educational and Scientific Institute of Applied Pharmacy of the National University of Pharmacy (Kharkiv, Ukraine). The experiments were performed in accordance with bioethical principles and standards in accordance with the provisions of the European Convention for the Protection of Vertebrate Animals Used for Experimental and Other Scientific Purposes (1986) and Council of Europe Directive 2010/63/EU (2010). All experiments have been approved by the Bioethics Commission of the National University of Pharmacy (protocol No. 3 from 10 September 2020).

The anticonvulsant effect of digoxin and its combinations with AEDs was studied under conditions of picrotoxin-, thiosemicarbazide-, strychnine- and camphor-induced seizures $[15,16]$. Animals were randomly divided into groups of 6 mice each: 1 group - control (untreated seizures), the remaining groups - animals with model seizures, which were administered carbamazepine, lamotrigine, as well as their combinations with digoxin.

Classical AEDs were administered once intragastrically (i.g.) as an aqueous suspension stabilized with tween-80, in conditionally effective $\left(\mathrm{ED}_{50}\right)$ and sub-effective $\left(1 / 2 \mathrm{ED}_{50}\right)$ doses $30 \mathrm{~min}$ before the administration of a convulsive agent: carbamazepine (Finlepsin, Teva Operations Poland) - at doses of 100 and $50 \mathrm{mg} / \mathrm{kg}$; lamotrigine (Lamictal, GlaxoSmithKline Pharmaceuticals, Poland) - at doses of 25 and $12.5 \mathrm{mg} / \mathrm{kg}$ [17]. This choice of doses is justified by the necessity to determine the possible potential effects of digoxin on the anticonvulsant action of drugs. Digoxin (Zdorovye, Ukraine) was administered once subcutaneously (s.c.) at a previously studied effective anticonvulsant dose of $0.8 \mathrm{mg} / \mathrm{kg}$ (which is equal to $1 / 10 \mathrm{LD}_{50}$ ) [10] $10-15$ minutes before seizure induction. Control animals received i.g. purified water in an appropriate volume $(0.1 \mathrm{ml}$ per $10 \mathrm{~g}$ of body weight).

According to the model of seizures as convulsants were used: picrotoxin (Sigma, USA) - aqueous solution, $2.5 \mathrm{mg} / \mathrm{kg}$ s.c.; thiosemicarbazide (Sigma, USA) - aqueous solution, $25 \mathrm{mg} / \mathrm{kg}$ intraperitoneally (i.p.); strychnine (strychnine nitrate, Sigma, USA) - aqueous solution, $1.2 \mathrm{mg} / \mathrm{kg}$ s.c.; camphor (Sigma, USA) oil solution, $1000 \mathrm{mg} / \mathrm{kg}$ i.p. $[15,16]$.

After administration of the convulsive agent, mice were placed in individual transparent plastic cylindrical boxes and the condition of the animals was continuously monitored for 1 hour (in the model of thiosemicarbazide seizures -4 hours). The severity of anticonvulsant effects of drugs and their combinations was assessed by the following indicators: 
latency of the convulsions; the number of clonic-tonic convulsions per one mouse; $\%$ of animals with clonic and tonic convulsions; the duration of the convulsive period (from the first to the last convulsion); and the lifetime of the animals before death (in mice with a lethal outcome) were calculated. The severity of seizures was evaluated according to a scale ranging from 1 to $6: 1$ - trembling; 2 - circus movement; 3 - clonic seizures; 4 - clonic-tonic seizures with a lateral position; 5 - tonic extension; 6 tonic extension leading to the death of the animal). If seizures were not observed within $1 \mathrm{~h}$, it was considered that the latency period was $60 \mathrm{~min}$ (in the model of thiosemicarbazide seizures - $240 \mathrm{~min}$ ) [18].

Statistical processing of the obtained results was performed using the software package STATISTICA 12 (StatSoft, USA) with the calculation of the mean value, standard error of mean, the level of statistical significance (p). Significance of differences between comparison groups was assessed by parametric Student's t-test in cases of normal distribution, non-parametric Mann-Whitney U-test - in its absence. The results, which were determined in an alternative form (lethality, \% of mice with clonic and tonic convulsions) were evaluated using the Fisher's criterion $(\varphi)$.

\section{Results}

Polymodal anticonvulsant properties of digoxin per se were verified by the pronounced effect of cardiac glycoside on the course of all studied chemo-induced seizures (Tables 1,2). In the picrotoxin-induced seizure model, digoxin not only significantly reduced lethality almost 4-fold relative to control $(p<0.05)$, but also statistically significantly increased the latency of the first seizure, reducing the $\%$ of animals with clonic and tonic convulsions, severity of paroxysms and duration of seizures. In the thiosemicarbazide-induced seizure model, the anticonvulsant potential of cardiac glycoside was determined both by a statistically significant reduction in animal death (lethality - $67 \%$ vs. $100 \%$ in the control group, $p<0.05$ ) and synchronous reduction $\%$ of animals with tonic paroxysms and probable prolongation the period of the first seizure. The antagonism of digoxin relative to the convulsive action of strychnine is not only a highly significant $(p<0.01)$ threefold decrease in lethality, but also a statistically significant fourfold increase in the latency time of first seizures $(p<0.01)$, a twofold reduction in the number of convulsion per animal (due to both clonic and tonic component) and the severity of seizures $(p<0.05)$ relative to control. In the camphor-induced seizure model, digoxin completely prevented the death of experimental mice in the group (lethality $-0 \%, p<0.01$ ), and causes a probable reduction in the severity of paroxysms relative to similar indicators of the group of animals with untreated seizures.

The results of studying the effect of digoxin on the anticonvulsant effect of carbamazepine are presented in Table 1.

Under paroxysms induced by picrotoxin, the anticonvulsant effect of carbamazepine in both doses is a statistically significant reduction in lethality $(p<0.01)$, as well as a significant reduction in seizure severity $(p<0.05)$ relative to control. In addition, under the influence of the drug at a $1 / 2 \mathrm{ED}_{50}$ there is a significant decrease in the $\%$ of mice with tonic seizures in the group.

The combined use of carbamazepine at a $1 / 2 \mathrm{ED}_{50}$ with digoxin is characterized by complete prevention of animal death (lethality $-0 \%$, like AED at an $\mathrm{ED}_{50}$ ), statistically significant relative to control $(p<0.05)$ reduce in the severity of seizures and the duration of the convulsive period. The combination of drugs also clearly prolongs the time to the onset of the first seizures - significant not only for control, but also for carbamazepine at both doses $(p<0.01)$.

In the thiosemicarbazide-induced seizure model, carbamazepine has a pronounced dose-dependent effect. Although the reducing effect of AED at both doses on lethality is completely comparable, at $\mathrm{ED}_{50}$, in contrast to a $1 / 2 \mathrm{ED}_{50}$, carbamazepine more than tripled the period of the first convulsions and halved the $\%$ of mice with clonic and tonic seizures $(p<0.01)$, increasing the lifetime of the animals before death $(p<0.05)$.

The addition of digoxin to carbamazepine at a $1 / 2$ $\mathrm{ED}_{50}$ not only completely prevents thiosemicarbazide-induced animal death (lethality $-0 \%, \mathrm{p}<0.01$ ), which is statistically significant not only for control, but also for digoxin per se and AED in both doses. In addition, the combined use of carbamazepine with digoxin significantly prolongs the latency period of the first convulsions, while reducing the number of animals with clonic and tonic seizures and the severity of paroxysms.

In terms of its effect on the experimental convulsive syndrome caused by strychnine, carbamazepine at a $1 / 2 \mathrm{ED}_{50}$ is slightly inferior to the effects of the drug at a $1 / 2 E_{50}$. Although in both doses AED significantly reduces lethality, prolongs the latent period of the first convulsions, reduce the $\%$ of animals with clonic and tonic convulsions and the severity of paroxysms, a more pronounced anticonvulsant effect is still inherent in carbamazepine in a conditionally effective dose. The effect of AED at an $\mathrm{ED}_{50}$ is additionally manifested in a statistically significant reduction in the number of clonic-tonic seizures per one mouse and a highly significant reduction in the duration of the convulsive period $(p<0.01)$.

The efficacy of the combined use of digoxin with carbamazepine at a $1 / 2 \mathrm{ED}_{50}$ in the model of strychnine-induced seizures is comparable to the anticonvulsant effect of classical AED at an $\mathrm{ED}_{50}$, which is confirmed by the same effect of drugs on all studied indicators of experimental paroxysms.

The anticonvulsant potential of carbamazepine at an $\mathrm{ED}_{50}$ in the camphor-induced seizure model is limited to a statistically significant effect on the number of paroxysms per mouse, the tonic component of seizures, the severity of convulsions, and the duration of the convulsive period. At a $1 / 2 \mathrm{ED}_{50}$ of $\mathrm{AED}$ significantly reduces animal lethality ( 17 vs. $67 \%$ in control, $\mathrm{p}<0.05$ ), reduces the $\%$ of mice with tonic convulsions and the severity of paroxysms. 
Table 1

Anticonvulsant effect of digoxin, carbamazepine and their combination in the primary generalized seizures in mice $(n=6)$

\begin{tabular}{|c|c|c|c|c|c|c|c|c|}
\hline \multirow[t]{2}{*}{ Group of animals } & \multirow[t]{2}{*}{ Latency, min } & \multirow{2}{*}{$\begin{array}{l}\text { Number of clon- } \\
\text { ic-tonic seizures } \\
\text { in } 1 \text { mouse }\end{array}$} & \multicolumn{2}{|c|}{$\begin{array}{c}\% \text { of mice with } \\
\text { convulsions }\end{array}$} & \multirow{2}{*}{$\begin{array}{l}\text { Severity of } \\
\text { seizures, } \\
\text { points }\end{array}$} & \multirow{2}{*}{$\begin{array}{l}\text { Period of sei- } \\
\text { zures, min }\end{array}$} & \multirow{2}{*}{$\begin{array}{l}\text { Time to } \\
\text { death, min }\end{array}$} & \multirow{2}{*}{$\begin{array}{l}\text { Lethali- } \\
\text { ty, } \%\end{array}$} \\
\hline & & & clonic & tonic & & & & \\
\hline \multicolumn{9}{|c|}{ Picrotoxin-induced seizures } \\
\hline $\begin{array}{l}\text { Control (untreat- } \\
\text { ed seizures) }\end{array}$ & $12.06 \pm 0.71$ & $4.83 \pm 1.40$ & 100 & 100 & $5.33 \pm 0.42$ & $29.77 \pm 5.93$ & $43.83 \pm 9.16$ & 67 \\
\hline Digoxin & $41.98 \pm 6.48 * *$ & $1.67 \pm 0.61$ & $67 *$ & $50 * *$ & $2.83 \pm 0.98^{*}$ & $3.44 \pm 1.56^{* *}$ & 33.40 & $17 *$ \\
\hline $\mathrm{CBZ}, \mathrm{ED}_{50}$ & $13.75 \pm 0.40^{\# \#}$ & $5.17 \pm 1.40$ & $100^{\#}$ & 83 & $3.83 \pm 0.17 *$ & $17.58 \pm 4.55^{\#}$ & - & $0 * *$ \\
\hline $\mathrm{CBZ}, 1 / 2 \mathrm{ED}_{50}$ & $16.41 \pm 1.41^{\# \#}$ & $4.33 \pm 1.05$ & $100^{\#}$ & $67 *$ & $3.67 \pm 0.21 *$ & $17.08 \pm 6.43$ & 37.95 & $17 *$ \\
\hline $\begin{array}{c}\mathrm{CBZ}_{1} 1 / 2 \mathrm{ED}_{50}+ \\
\text { Digoxin }\end{array}$ & $36.48 \pm 4.37 * * \$ \S \circ \circ$ & $4.00 \pm 0.89$ & $100^{\#}$ & 83 & $3.83 \pm 0.17 *$ & $12.95 \pm 3.88^{*}$ & - & $0 * *$ \\
\hline \multicolumn{9}{|c|}{ Thiosemicarbazide-induced seizures } \\
\hline $\begin{array}{l}\text { Control (untreat- } \\
\text { ed seizures) }\end{array}$ & $54.72 \pm 2.92$ & $1.83 \pm 0.40$ & 100 & 100 & $6.00 \pm 0.00$ & $7.62 \pm 3.88$ & $62.34 \pm 4.27$ & 100 \\
\hline Digoxin & $75.98 \pm 4.75 *$ & $1.50 \pm 0.34$ & 100 & $67 *$ & $5.00 \pm 0.63$ & $5.03 \pm 2.95$ & $76.84 \pm 3.50$ & $67^{*}$ \\
\hline $\mathrm{CBZ}, \mathrm{ED}_{50}$ & $172.13 \pm 30.76^{* * \#}$ & $2.17 \pm 1.28$ & $50 * * \#$ & $50 * *$ & $3.00 \pm 1.34$ & $13.14 \pm 7.25$ & $130.55 \pm 7.09 *$ & $50 * *$ \\
\hline $\mathrm{CBZ}, 1 / 2 \mathrm{ED}_{50}$ & $108.58 \pm 28.47$ & $3.00 \pm 1.03$ & 83 & 83 & $4.33 \pm 0.95$ & $35.17 \pm 15.42$ & $113.68 \pm 28.93$ & $50 * *$ \\
\hline $\begin{array}{c}\mathrm{CBZ}_{1}^{1 / 2} \mathrm{ED}_{50}+ \\
\text { Digoxin }\end{array}$ & $161.34 \pm 25.20 * * \# \#$ & $1.50 \pm 0.62$ & $67 * \#$ & $50 * *$ & $2.50 \pm 0.81 * *$ & $13.45 \pm 7.95$ & - & 0 **\#\#§ऽo \\
\hline \multicolumn{9}{|c|}{ Strychnine-induced seizures } \\
\hline $\begin{array}{l}\text { Control (untreat- } \\
\text { ed seizures) }\end{array}$ & $7.73 \pm 0.46$ & $1.33 \pm 0.21$ & 100 & 100 & $6.00 \pm 0.00$ & $1.15 \pm 0.64$ & $8.88 \pm 0.76$ & 100 \\
\hline Digoxin & $31.28 \pm 9.17 * *$ & $0.67 \pm 0.21 *$ & $67 *$ & $33 * *$ & $3.00 \pm 1.10^{*}$ & $0.33 \pm 0.19$ & $18.55 \pm 2.90$ & $33 * *$ \\
\hline $\mathrm{CBZ}, \mathrm{ED}_{50}$ & $51.89 \pm 8.11 * *$ & $0.17 \pm 0.17 * *$ & $17 * * \#$ & $17 * *$ & $0.67 \pm 0.67 * *$ & $0.02 \pm 0.02 * *$ & - & $0 * * \#$ \\
\hline $\mathrm{CBZ}, 1 / 2 \mathrm{ED}_{50}$ & $33.97 \pm 11.73 *$ & $0.83 \pm 0.40$ & $50 * *$ & $50 * *$ & $2.33 \pm 1.09 * *$ & $0.39 \pm 0.22$ & $8.71 \pm 3.50$ & $33 * *$ \\
\hline $\begin{array}{c}\mathrm{CBZ}^{1 / 2} \mathrm{ED}_{50}+ \\
\text { Digoxin }\end{array}$ & $51.11 \pm 8.89^{*}$ & $0.17 \pm 0.17 * *$ & $17 * * \#$ & $17 * *$ & $0.67 \pm 0.67 * *$ & $0.02 \pm 0.02 * *$ & - & $0^{* * \#}$ \\
\hline \multicolumn{9}{|c|}{ Camphor-induced seizures } \\
\hline $\begin{array}{l}\text { Control (untreat- } \\
\text { ed seizures) }\end{array}$ & $4.96 \pm 0.75$ & $7.33 \pm 1.12$ & 100 & 100 & $5.33 \pm 0.42$ & $46.26 \pm 10.90$ & $40.86 \pm 12.62$ & 67 \\
\hline Digoxin & $6.22 \pm 0.36$ & $5.33 \pm 0.42$ & 100 & 100 & $4.00 \pm 0.00 *$ & $44.85 \pm 7.42$ & - & $0 * *$ \\
\hline $\mathrm{CBZ}, \mathrm{ED}_{50}$ & $16.27 \pm 8.83$ & $2.33 \pm 0.56^{* \#}$ & 83 & $50 * * \#$ & $3.00 \pm 0.63^{*}$ & $9.09 \pm 2.88^{* \#}$ & $21.32 \pm 1.38$ & $33^{\#}$ \\
\hline $\mathrm{CBZ}, 1 / 2 \mathrm{ED}_{50}$ & $8.33 \pm 1.31$ & $4.67 \pm 1.33$ & 100 & 50 **\#\# & $3.83 \pm 0.48^{*}$ & $15.05 \pm 4.79^{* \#}$ & 31.35 & $17^{*}$ \\
\hline $\begin{array}{c}\mathrm{CBZ}_{1} 1 / 2 \mathrm{ED}_{50}+ \\
\text { Digoxin }\end{array}$ & $10,34 \pm 1,29 * \#$ & $1,00 \pm 0,00 * * \# \S \bigcirc \circ$ & 100 & $17 * * \#$ & $3.17 \pm 0.17$ **\# & $0.13 \pm 0.01 * * \# \# \diamond \circ$ & 10.08 & $17^{*}$ \\
\hline
\end{tabular}

Note: $n$ - number of animals in each group; $C B Z$ - carbamazepine; $*-p<0.05$ when compared with control; ** $-p<0.01$ when compared with control; ${ }^{-}-p<0.05$ when compared with digoxin, ${ }^{\#}-p<0.01$ when compared with digoxin; $\xi_{-}-p<0.05$ when compared with carbamazepine at an $E D_{50} ;{ }^{\xi}-p<0.01$ when compared with carbamazepine at an $E D_{50},{ }^{\circ}-p<0.05$ when compared with carbamazepine at a $1 / 2 E D_{50} ;{ }^{\circ}-p<0.01$ when compared with carbamazepine at a $1 / 2 E D_{50}$

The combination of carbamazepine at a $1 / 2 \mathrm{ED}_{50}$ with digoxin causes a pronounced anticonvulsant effect, which in terms of the effect on individual studied indicators probably exceeds the effect of not only the individual components of the combination, but also $\mathrm{AED}$ at an $\mathrm{ED}_{50}$. Thus, the combination significantly reduces the lethality of animals in the group $(p<0.05)$, statistically significantly prolongs the time of the first paroxysms, reducing the number of convulsions per one mouse (mainly due to the tonic component), as well as the severity of convulsions and the duration of the convulsive period. Although the effectiveness of the combination of carbamazepine and digoxin under camphor-induced seizures (lethality $17 \%$ or $1 / 6$ ) seems smaller than against monotherapy of digoxin (lethality $0 \%$ or $0 / 6$ ), this difference with such a number of animals in the experimental groups has no statistical significance.
The results of the study of the effect of digoxin on the spectrum of anticonvulsant action of lamotrigine are shown in Table 2.

The ambiguity of the effect of lamotrigine on the course of picrotoxin seizures was found, on the one hand, due to the absence of effect of AED at an $\mathrm{ED}_{50}$, and on the other - statistically significant prolongation of the latent period of the first convulsion against the background of significant $(p<0.05)$ increase in animal lethality under the action of the drug at an $\mathrm{ED}_{50}$.

Combined use of lamotrigine at $1 / 2 \mathrm{ED}_{50}$ with digoxin, although not affecting the mortality of animals in the experimental group, still causes a probable prolongation of the latent period of the first convulsions and a decrease in \% of mice with tonic convulsions, but inferior to the effectiveness of digoxin monotherapy. 
Table 2

Anticonvulsant effect of digoxin, lamotrigine and their combination in the primary generalized seizures in mice $(n=6)$

\begin{tabular}{|c|c|c|c|c|c|c|c|c|}
\hline \multirow{2}{*}{$\begin{array}{l}\text { Group of ani- } \\
\text { mals }\end{array}$} & \multirow[t]{2}{*}{ Latency, min } & \multirow{2}{*}{$\begin{array}{l}\text { Number of clon- } \\
\text { ic-tonic seizures } \\
\text { in } 1 \text { mouse }\end{array}$} & \multicolumn{2}{|c|}{$\begin{array}{c}\% \text { of mice with } \\
\text { convulsions }\end{array}$} & \multirow{2}{*}{$\begin{array}{c}\text { Severity of sei- } \\
\text { zures, points }\end{array}$} & \multirow{2}{*}{$\begin{array}{l}\text { Period of sei- } \\
\text { zures, min }\end{array}$} & \multirow{2}{*}{$\begin{array}{l}\text { Time to death, } \\
\min \end{array}$} & \multirow{2}{*}{$\begin{array}{l}\text { Lethali- } \\
\text { ty, } \%\end{array}$} \\
\hline & & & clonic & tonic & & & & \\
\hline \multicolumn{9}{|c|}{ Picrotoxin-induced seizures } \\
\hline $\begin{array}{c}\text { Control (untreat- } \\
\text { ed seizures) }\end{array}$ & $12.06 \pm 0.71$ & $4.83 \pm 1.40$ & 100 & 100 & $5.33 \pm 0.42$ & $29.77 \pm 5.93$ & $43.83 \pm 9.16$ & 67 \\
\hline Digoxin & $41.98 \pm 6.48 * *$ & $1.67 \pm 0.61$ & $67 *$ & $50 * *$ & $2.83 \pm 0.98^{*}$ & $3.44 \pm 1.56^{* *}$ & 33.40 & $17 *$ \\
\hline LTG, $\mathrm{ED}_{50}$ & $15.16 \pm 1.89^{\# \#}$ & $6.50 \pm 0.56^{\# \#}$ & $100^{\#}$ & $100^{\# \#}$ & $5.67 \pm 0.33^{\#}$ & $21.02 \pm 1.71^{\# \#}$ & $34.38 \pm 2.22$ & $83^{\# \#}$ \\
\hline $\mathrm{LTG}, 1 / 2 \mathrm{ED}_{50}$ & $16.43 \pm 1.58 * \#$ & $4.50 \pm 0.56^{\#}$ & $100^{\#}$ & $100^{\# \#}$ & $6.00 \pm 0.00^{\# \#}$ & $21.43 \pm 2.73^{\# \#}$ & $37.86 \pm 3.60$ & $100 * \#$ \\
\hline $\begin{array}{c}\mathrm{LTG}, 1 / 2 \\
\mathrm{ED}_{50}+\text { Digoxin }\end{array}$ & $23.89 \pm 4.70^{* * \# \S}$ & $2.50 \pm 0.43$ §̧० & $100^{\#}$ & $67 * \S 0$ & $5.00 \pm 0.63$ & $15.74 \pm 4.76^{\#}$ & $41.36 \pm 3.81$ & $67^{\# 0}$ \\
\hline \multicolumn{9}{|c|}{ Thiosemicarbazide-induced seizures } \\
\hline $\begin{array}{l}\text { Control (untreat- } \\
\text { ed seizures) }\end{array}$ & $54.72 \pm 2.92$ & $1.83 \pm 0.40$ & 100 & 100 & $6.00 \pm 0.00$ & $7.62 \pm 3.88$ & $62.34 \pm 4.27$ & 100 \\
\hline Digoxin & $75.98 \pm 4.75^{*}$ & $1.50 \pm 0.34$ & 100 & $67 *$ & $5.00 \pm 0.63$ & $5.03 \pm 2.95$ & $76.84 \pm 3.50$ & $67 *$ \\
\hline LTG, $\mathrm{ED}_{50}$ & $107.11 \pm 26.98 * *$ & $5.00 \pm 1.26^{*}$ & 83 & 83 & $4.50 \pm 0.96$ & $63.78 \pm 15.45^{*}$ & $144.33 \pm 7.97^{*}$ & $50 * *$ \\
\hline $\mathrm{LTG}, 1 / 2 \mathrm{ED}_{50}$ & $83.57 \pm 10.99 *$ & $3.33 \pm 0.84$ & 100 & $100^{\#}$ & $5.33 \pm 0.42$ & $55.27 \pm 16.86^{* \#}$ & $126.32 \pm 21.98 *$ & $67 *$ \\
\hline $\begin{array}{c}\text { LTG, } 1 / 2 \\
\mathrm{ED}_{50}+\text { Digoxin }\end{array}$ & $92.43 \pm 9.12 * *$ & $3.33 \pm 0.61^{\#}$ & 100 & $100^{\#}$ & $5.33 \pm 0.42$ & $47.50 \pm 10.44 * * \#$ & $155.99 \pm 1.88^{* \#}$ & $67^{*}$ \\
\hline \multicolumn{9}{|c|}{ Strychnine-induced seizures } \\
\hline $\begin{array}{l}\text { Control (untreat- } \\
\text { ed seizures) }\end{array}$ & $7.73 \pm 0.46$ & $1.33 \pm 0.21$ & 100 & 100 & $6.00 \pm 0.00$ & $1.15 \pm 0.64$ & $8.88 \pm 0.76$ & 100 \\
\hline Digoxin & $31.28 \pm 9.17 * *$ & $0.67 \pm 0.21 *$ & $67 *$ & $33 * *$ & $3.00 \pm 1.10^{*}$ & $0.33 \pm 0.19$ & $18.55 \pm 2.90$ & $33 * *$ \\
\hline LTG, ED $_{50}$ & $27.49 \pm 10.32 *$ & $1.50 \pm 0.62$ & $67 *$ & $50 * *$ & $3.17 \pm 1.08 * *$ & $8.18 \pm 4.85$ & 10.45 & $17 * *$ \\
\hline LTG, $1 / 2 \mathrm{ED}_{50}$ & $26.12 \pm 10.77^{*}$ & $1.17 \pm 0.40$ & $67 *$ & $50 * *$ & $2.83 \pm 0.98 * *$ & $2.79 \pm 2.01$ & 9.98 & $17 * *$ \\
\hline $\begin{array}{c}\text { LTG, } 1 / 2 \\
\mathrm{ED}_{50}+\text { Digoxin }\end{array}$ & $60.00 \pm 0.00 * * \# \bigcirc \circ$ & $0.00 \pm 0.00 * * \# \S \circ$ & $0 * * \# \S \S \circ 0$ & $0 * * \# \S \bigcirc \circ$ & $0.00 \pm 0.00 * * \# \S \circ$ & $0.00 \pm 0.00 * * \# \S \circ$ & - & $0^{* * \#}$ \\
\hline \multicolumn{9}{|c|}{ Camphor-induced seizures } \\
\hline $\begin{array}{c}\text { Control (untreat- } \\
\text { ed seizures) }\end{array}$ & $4.96 \pm 0.75$ & $7.33 \pm 1.12$ & 100 & 100 & $5.33 \pm 0.42$ & $46.26 \pm 10.90$ & $40.86 \pm 12.62$ & 67 \\
\hline Digoxin & $6.22 \pm 0.36$ & $5.33 \pm 0.42$ & 100 & 100 & $4.00 \pm 0.00 *$ & $44.85 \pm 7.42$ & - & $0 * *$ \\
\hline LTG, ED $_{50}$ & $8.08 \pm 2.35$ & $4.67 \pm 0.67$ & 100 & 100 & $5.00 \pm 0.45$ & $39.61 \pm 9.34$ & $49.85 \pm 19.26$ & $50^{\# \#}$ \\
\hline LTG, $1 / 2 \mathrm{ED}_{50}$ & $5.40 \pm 1.20$ & $4.00 \pm 0.52^{*}$ & 100 & 100 & $5.00 \pm 0.45$ & $21.42 \pm 5.16^{\#}$ & $27.84 \pm 9.59$ & $50^{\# \#}$ \\
\hline $\begin{array}{c}\text { LTG, } 1 / 2 \\
\mathrm{ED}_{50}+\text { Digoxin }\end{array}$ & $18.78 \pm 8.41$ *\#о & $3.50 \pm 1.18^{*}$ & 83 & 83 & $3.33 \pm 0.67 * \S ం$ & $14.85 \pm 5.19^{* \#}$ & $25.46 \pm 9.82$ & $50^{\# \#}$ \\
\hline
\end{tabular}

Note: $n$ - number of animals in each group; LTG - lamotrigine; $*-p<0.05$ when compared with control; ** $-p<0.01$ when compared with control; \# $-p<0.05$ when compared with digoxin, \# $-p<0.01$ when compared with digoxin; $\$$ $p<0.05$ when compared with lamotrigine at an $E D_{50} ; \xi \xi-p<0.01$ when compared with lamotrigine at an $E D_{50} ;{ }^{\circ}-$ $p<0.05$ when compared with lamotrigine at a $1 / 2 E D_{50} ;{ }^{\circ}-p<0.01$ when compared with lamotrigine at a $1 / 2 E D_{50}$

The addition of the cardiac glycoside digoxin to the lamotrigine at a $1 / 2 \mathrm{ED}_{50}$ does not provide significant advantages in anticonvulsant action - the effect of the combination does not differ in its effectiveness from the action of AED at low dose, and according to the influence on some studied indicators of experimental paroxysms (in particular, the number of seizures per one mouse, $\%$ of animals with tonic convulsions, the duration of the convulsive period, etc.) is even significantly $(p<0.05)$ inferior to digoxin monotherapy.

Comparable anticonvulsant efficacy of lamotrigine at both doses was verified in a strychnine-induced seizure model. Under the influence of AED, there was a statistically significant prolongation of the latent period of the first convulsions relative to the control, a decrease in the percentage of mice with clonic and tonic paroxysms, the severity of convulsions, and a significant reduction in animal lethality (17\% vs. $100 \%$ in control, $p<0.01)$.
Digoxin significantly increases the anticonvulsant potential of lamotrigine at a $1 / 2 \mathrm{ED}_{50}$, significantly exceeding the effect of monotherapy with individual drugs - the combined use of cardiac glycoside with classical AED has the maximum protective effect, completely preventing the development of strychnine-induced seizures.

The effect of lamotrigine on the camphor-induced seizures is limited only by a statistically significant reduction in the number of clonic-tonic convulsion per one mouse under the influence of AED at a $1 / 2 \mathrm{ED}_{50}(p<0.05$ relative to control) in the absence of significant effect of both conditionally effective and sub-effective doses of the drug on other studied parameters of experimental seizures.

The combination of lamotrigine at a $1 / 2 \mathrm{ED}_{50}$ and digoxin prolongs the onset of the first paroxysms (significantly relative to control, digoxin per se, and AED at a sub-effective dose, $p<0.05$ ), reduces the number of clonic-tonic convulsions per one mouse $(p<0.05$ relative to 
the same group of animals with untreated convulsions), as well as statistically significantly reduces the severity of convulsions (relative to control and AED in both doses, $p<0.05)$ and the duration of the convulsive period - relative to control groups and digoxin per se. However, in terms of the effect on the main integral indicator of efficiency - \% lethality of animals - the combination does not differ significantly from the similar indicator of the control group, but also is statistically significantly inferior $(p<0.01)$ to digoxin monotherapy.

\section{Discussion}

The different pathogenesis of experimental seizures makes it possible to assess the possible profile of the molecular effect of digoxin on epileptogenesis, as well as to further establish some neurochemical mechanisms of interaction of cardiac glycoside with known AEDs such as carbamazepine and lamotrigine.

The convulsive action of picrotoxin is associated with blockade of the chlorine ionophore $\mathrm{GABA}_{\mathrm{A}}$-receptor and impaired GABA-ergic inhibitory neurotransmission [19]. The mechanism of convulsive action of thiosemicarbazide is the inhibition of the enzyme glutamate decarboxylase, which leads to the synchronous accumulation of the excitatory amino acid glutamate and depletion of the cerebral pool of GABA [20]. The convulsive effect of strychnine is due to blockade of postsynaptic glycine receptors [21]. Polymodal convulsive action of camphor is probably the result of impaired energy metabolism of neurons [22] and imbalance of cerebral monoamines [23].

Although the pronounced effect of sub-cardiotonic dose of digoxin on all four models of experimental seizures may indicate a complex mechanism of action of the drug on various neurochemical links in the development of paroxysms (such as increased GABA- and glycinergic neurotransmission, blockade of glutamate effects, restoration of tissue respiration of neurons, etc.), however, normalization of the transmembrane sodium current is likely - a key factor in maintaining ionic homeostasis of neurons, the violation of which is the final and main molecular predictor of seizure development. This effect is apparently achieved due to the effect on the neuronal $\mathrm{Na}^{+}$/ $\mathrm{K}^{+}$-ATPase, an enzyme that transports sodium ions across excitable cell membranes [24, 25]. It has been shown that at low doses, cardiac glycosides activate (rather than inhibit) $\mathrm{Na}^{+} / \mathrm{K}^{+}$-ATPase, including neurons, thereby maintaining resting potential $[26,27]$.

The pronounced anticonvulsant potential of carbamazepine, primarily due to (but not limited to) the blockade of sodium channels in neuronal membranes [28], has been verified in most experimental convulsive models. This further confirms the feasibility of its widespread use in the treatment of various forms of epilepsy. Digoxin, however, significantly enhances the anticonvulsant effect of carbamazepine at low doses. In models of picrotoxin-, thiosemicarbazide- and camphor-induced seizures, the effectiveness of the combined use of carbamazepine and digoxin probably exceeds the effect not only of monotherapy with appropriate drugs, but also the effect of AEDs in a higher, relatively effective dose. In the long term, this makes it possible to reduce the doses of classical AEDs (and, as a consequence, the risks of side effects) without losing the effectiveness of treatment. In addition, the clear modulation by digoxin of a moderate anticonvulsant effect of carbamazepine under conditions of camphor paroxysms indicates the possibility of the effect of such a combination on the course of refractory seizures.

Moderately narrow spectrum of anticonvulsant action of lamotrigine, presumably associated with limited influence of AED on certain neurochemical mechanisms of seizures (in particular, due to blockade of sodium channels, suppression of glutamatergic and, obviously, enhancing of glycinergic neurotransmission [29]) is confirmed by its pronounced effect on the model of thiosemicarbazide and strychnine convulsions in the absence of antagonism with picrotoxin and camphor. Digoxin somewhat enhances the effect of lamotrigine by the effect on individual studied indicators of the course of paroxysms induced by picrotoxin, thiosemicarbazide and camphor. However, even under such conditions, the combination is not able to significantly reduce lethality - the main integral indicator of the effectiveness of therapy. The most pronounced potentiating effect of digoxin was found only when combined with lamotrigine in the model of strychnine seizures, which provides the maximum protective effect - complete prevention of seizures.

Thus, digoxin has its own polymodal anticonvulsant effect, which is constantly manifested in models of paroxysms with different neurochemical mechanisms. In addition, digoxin has potentiating properties: cardiac glycoside significantly enhances the anticonvulsant effect of carbamazepine and moderately lamotrigine, which provides a protective effect of sub-effective doses of classical AEDs, including models with non-profile for drugs mechanisms of action. In the long run, this will not only reduce the dose of AEDs and, consequently, the risks of side effects without losing the effectiveness of treatment, but also the ability to affect resistant seizures.

Study limitations. The influence of digoxin on the spectrum of anticonvulsant action of another widespread antiepileptic drugs (such as sodium valproate, levetiracetam, topiramate, clonazepam and phenobarbital) remains unclear.

Prospects for further research. Elucidation of the effect of digoxin on the spectrum of anticonvulsant activity of sodium valproate, levetiracetam, topiramate, clonazepam and phenobarbital as well as determination of neurochemical mechanisms of anticonvulsant action of digoxin - both in monotherapy and in combinations with well-known antiepileptic drugs.

\section{Conclusion}

The effect of digoxin in sub-cardiotonic dose on the anticonvulsant potential of carbamazepine and lamotrigine under conditions of picrotoxin-, thiosemicarbazide-, strychnine- and camphor-induced seizures was studied. It was found that digoxin not only has its own 
permanent anticonvulsant effect on different models of paroxysms with different neurochemical mechanisms of development, but also significantly enhances the anticonvulsant potential of carbamazepine (to a lesser extent - lamotrigine) regardless of the pathogenesis of experimental paroxysms. Based on the results, it can be concluded that digoxin has a high potential as an adjuvant medicine in complex epilepsy treatment because it enhances the efficiency of low-dose traditional anticonvulsants carbamazepine and lamotrigine.

\section{Conflict of interests} interest.

The authors declare that they have no conflicts of

\section{Funding}

The work was performed as part of the basic scientific study No. 0120U102460 "Rationale for improving the treatment of multidrug-resistant epilepsy through the combined use of classic anticonvulsants with other drugs", which is performed at the expense of the State Budget of Ukraine.

\section{Acknowledgement}

Authors express their highest esteem and thanks to Deputy Director for Science of the Educational and Scientific Institute of Applied Pharmacy of the National University of Pharmacy, researcher Tatiana Yudkevich for her help in hosting the research.

\section{References}

1. Perucca, E. (2019). Antiepileptic drugs: evolution of our knowledge and changes in drug trials. Epileptic disorders, 21 (4), $319-329$.

2. Löscher, W., Klein, P. (2021). The Pharmacology and Clinical Efficacy of Antiseizure Medications: From Bromide Salts to Cenobamate and Beyond. CNS Drugs, 35 (9), 935-963. doi: http://doi.org/10.1007/s40263-021-00827-8

3. Kalilani, L., Sun, X., Pelgrims, B., Noack-Rink, M., Villanueva, V. (2018). The epidemiology of drug-resistant epilepsy: A systematic review and meta-analysis. Epilepsia, 59 (12), 2179-2193. doi: http://doi.org/10.1111/epi.14596

4. Pérez-Pérez, D., Frías-Soria, C. L., Rocha, L. (2021). Drug-resistant epilepsy: From multiple hypotheses to an integral explanation using preclinical resources. Epilepsy \& Behavior, 121. doi: http://doi.org/10.1016/j.yebeh.2019.07.031

5. Łukawski, K., Czuczwar, S. J. (2021). Understanding mechanisms of drug resistance in epilepsy and strategies for overcoming it. Expert Opinion on Drug Metabolism \& Toxicology, 17 (9), 1075-1090. doi: http://doi.org/10.1080/17425255.2021.1959912

6. Borowicz, K. K., Banach, M. (2014). Antiarrhythmic drugs and epilepsy. Pharmacological Reports, 66 (4), 545-551. doi: http://doi.org/10.1016/j.pharep.2014.03.009

7. Zeiler, F. A., Zeiler, K. J., Kazina, C. J., Teitelbaum, J., Gillman, L. M., West, M. (2015). Lidocaine for status epilepticus in adults. Seizure, 31, 41-48. doi: http://doi.org/10.1016/j.seizure.2015.07.003

8. Elgarhi, R., Shehata, M. M., Abdelsameea, A. A., Salem, A. E. (2020). Effects of Diclofenac Versus Meloxicam in Pentylenetetrazol-Kindled Mice. Neurochemical Research, 45 (8), 1913-1919. doi: http://doi.org/10.1007/s11064-020-03054-7

9. Scicchitano, F., Constanti, A., Citraro, R., Sarro, G., Russo, E. (2015). Statins and epilepsy: preclinical studies, clinical trials and statin-anticonvulsant drug interactions. Current Drug Targets, 16 (7), 747-756. doi: http://doi.org/10.2174/1389450116666150330114850

10. Markova, I. V., Mikhailov, I. B., Guzeva, V. I. (1991). Digoksin-aktivnoe protivoépilepticheskoe sredstvo. Farmakologiia i toksikologiia, 54 (5), 52-54.

11. Shtrygol, S. Yu., Shtrygol, D. V. (2010). Digoksin kak protivoepilepticheskoe sredstvo u detei (kliniko-eksperimentalnoe issledovanie) Ukrainskyi medychnyi almanakh, 13 (4), 164.

12. Tsyvunin, V., Shtrygol', S., Shtrygol', D. (2020). Digoxin enhances the effect of antiepileptic drugs with different mechanism of action in the pentylenetetrazole-induced seizures in mice. Epilepsy Research, 167. doi: http://doi.org/10.1016/ j.eplepsyres.2020.106465

13. Tsyvunin, V., Shtrygol', S., Shtrygol', D., Mishchenko, M., Kapelka, I., Taran, A. (2021). Digoxin potentiates the anticonvulsant effect of carbamazepine and lamotrigine against experimental seizures in mice. Thai Journal of Pharmaceutical Sciences, 45 (3), $165-171$.

14. Lidster, K., Jefferys, J. G., Blümcke, I., Crunelli, V., Flecknell, P., Frenguelli, B. G. et. al. (2016). Opportunities for improving animal welfare in rodent models of epilepsy and seizures. Journal of Neuroscience Methods, 260, 2-25. doi: http:// doi.org/10.1016/j.jneumeth.2015.09.007

15. Kallman, M. J.; Hock, F. J. (Ed.) (2016). Anti-Epileptic Activity. Drug Discovery and Evaluation: Pharmacological Assays. Switzerland: Springer International Publishing, 1215-1306. doi: http://doi.org/10.1007/978-3-319-05392-9_28

16. Mironov, A. N., Bunyatyan, N. D., Vasileva A. N. (2012). Rukovodstvo po provedeniiu doklinicheskih issledovanii lekarstvennyh sredstv. Moscow: Grif and K., 235-250.

17. Duveau, V., Pouyatos, B., Bressand, K., Bouyssières, C., Chabrol, T., Roche, Y. et. al. (2016). Differential Effects of Antiepileptic Drugs on Focal Seizures in the Intrahippocampal Kainate Mouse Model of Mesial Temporal Lobe Epilepsy. CNS Neuroscience \& Therapeutics, 22 (6), 497-506. doi: http://doi.org/10.1111/cns.12523

18. El Kayal, W. M., Shtrygol, S. Y., Zalevskyi, S. V., Shark, A. abu, Tsyvunin, V. V., Kovalenko, S. M. et. al. (2019). Synthesis, in vivo and in silico anticonvulsant activity studies of new derivatives of 2-(2,4-dioxo-1,4-dihydroquinazolin-3(2H)-yl)acetamide. European Journal of Medicinal Chemistry, 180, 134-142. doi: http://doi.org/10.1016/j.ejmech.2019.06.085

19. Olsen, R. W. (2006). Picrotoxin-like channel blockers of GABAA receptors. Proceedings of the National Academy of Sciences, 103 (16), 6081-6082. doi: http://doi.org/10.1073/pnas.0601121103

20. Salazar, P., Tapia, R. (2015). Epilepsy and hippocampal neurodegeneration induced by glutamate decarboxylase inhibitors in awake rats. Epilepsy Research, 116, 27-33. doi: http://doi.org/10.1016/j.eplepsyres.2015.06.014 
21. Otter, J., D’Orazio, J. L. (2021). Strychnine Toxicity. StatPearls Publishing. Available at: https://www.ncbi.nlm.nih.gov/ books/NBK459306/

22. Narayan, S., Singh, N. (2012). Camphor poisoning - An unusual cause of seizure. Medical Journal Armed Forces India, 68 (3), 252-253. doi: http://doi.org/10.1016/j.mjafi.2011.11.008

23. Park, T.-J., Seo, H.-K., Kang, B.-J., Kim, K.-T. (2001). Noncompetitive inhibition by camphor of nicotinic acetylcholine receptors. Biochemical Pharmacology, 61 (7), 787-793. doi: http://doi.org/10.1016/s0006-2952(01)00547-0

24. Funck, V. R., Ribeiro, L. R., Pereira, L. M., de Oliveira, C. V., Grigoletto, J., Della-Pace, I. D. et. al. (2015). Contrasting effects of $\mathrm{Na}+, \mathrm{K}+$-ATPase activation on seizure activity in acute versus chronic models. Neuroscience, 298, 171-179. doi: http://doi.org/ 10.1016/j.neuroscience.2015.04.031

25. Krishnan, G. P., Filatov, G., Shilnikov, A., Bazhenov, M. (2015). Electrogenic properties of the Na+/K+ATPase control transitions between normal and pathological brain states. Journal of Neurophysiology, 113 (9), 3356-3374. doi: http://doi.org/10.1152/ jn.00460.2014

26. Sergeev, P. V., Shimanovskii, N. L. (2010). Biokhimicheskaia farmakologiia. Moscow: Moscow Information Agency, 624.

27. Patocka, J., Nepovimova, E., Wu, W., Kuca, K. (2020). Digoxin: Pharmacology and toxicology - A review. Environmental Toxicology and Pharmacology, 79. doi: http://doi.org/10.1016/j.etap.2020.103400

28. Alrashood, S. T. (2016). Carbamazepine. Profiles of Drug Substances, Excipients and Related Methodology. Elsevier Inc., 133-321. doi: http://doi.org/10.1016/bs.podrm.2015.11.001

29. Sills, G. J., Rogawski, M. A. (2020). Mechanisms of action of currently used antiseizure drugs. Neuropharmacology, 168. doi: http://doi.org/10.1016/j.neuropharm.2020.107966

Received date 26.10.2021

Accepted date 07.12.2021

Published date 13.12.2021

Vadim Tsyvunin, PhD, Assistant, Department of Pharmacology and Pharmacotherapy, National University of Pharmacy

Pushkinska str., 53, Kharkiv, Ukraine, 61002

Sergiy Shtrygol'*, Doctor of Medical Sciences, Professor, Department of Pharmacology and Pharmacotherapy, National University of Pharmacy, Pushkinska str., 53, Kharkiv, Ukraine, 61002

Ihnat Havrylov, Postgraduate Student, Department of Pharmacology and Pharmacotherapy, National University of Pharmacy, Pushkinska str., 53, Kharkiv, Ukraine, 61002

Diana Shtrygol', PhD, Associate Professor, Department of Neurology, Psychiatry, Narcology and Medical Psychology, School of Medicine, V. N. Karazin Kharkiv National University, Svobody sq., 4, Kharkiv, Ukraine, 61022

*Corresponding author: Sergiy Shtrygol',e-mail: shtrygol@ukr.net 